\title{
A Study of the Establishment of Internal Audit Quality Control System in Universities
}

\author{
Sun Li \\ Audit Office of Hainan University, Haikou 570228, China
}

Keywords: Internal audit in universities; Audit quality; Control system; Establishment measures

\begin{abstract}
This paper aims to analyze the establishment measures of internal audit quality control system in universities. Specifically, based on the exposition of the concept and connotation of internal control audit quality in universities, the current problems of internal audit control in universities were analyzed from external and internal aspects, and the establishment measures of the control system were analyzed, hoping to contribute to optimizing the internal audit quality in universities, and promoting the development process of universities.
\end{abstract}

\section{Introduction}

Internal audit is one of the important factors of internal control in universities, its practical value is embodied in that it supervises the operation mode of economic activities in universities, and optimizes school management control, thereby reducing the probability of risks, ensuring the use ratio of the educational funds and helping universities implement various development goals. But at present, the operating quality of internal audit in most universities in China is difficult to be effectively safeguarded, and the supervision and service functions of internal audit are not fully manifested, hence, in this context, it is particularly important to establish the internal audit quality control system. The establishment measures for the system have been under investigation by numerous university auditors, and will be analyzed in detail in this paper.

\section{Internal control audit quality in universities}

\subsection{Concept definition}

In terms of nature, there is almost no difference between the quality of internal control audit in universities and that of ordinary internal control audit. Compared with other economic work, the internal audit work likewise attaches importance to economic benefits [1], but the difference is that internal audit departments and related personnel in universities must observe various processes set by universities and make efforts to achieve some goal. The tenet of improving the operating efficiency of internal control audit work in universities is not to acquire some funds for the development of various undertakings of universities from the external environment, but to cohesively enhance the benefits and efficiency of internal audit work in universities, to reduce the occurrence probability of financial risk and audit risk, and to maintain and enhance the quality of internal administrative control in universities.

\subsection{Connotation}

The extent of function display of internal audit departments of universities is related to the operating quality of the internal audit, and reasonable management and control of the internal audit operational mode is an effective basis for improving the quality of internal audit in universities. With the assistance of effective control methods, auditors can obtain considerable audit results with low audit resource input, thus helping universities to realize certain audit objectives in a short time, enhancing the level and quality of internal audit work, and continuously developing and optimizing internal audit system in universities in practice. 


\section{The current situation of internal audit control in universities}

\subsection{Analysis from the perspective of external factors.}

Firstly, the operation of university internal audit work has not yet been supported by perfect legal system. Although the legal system of internal audit in universities is under constant reform, possesses certain foundation and plays a guiding role in the operation of internal audit work, the system still has some defects, which is embodied in the systematic lack of relevant provisions, and the absence of mechanism related to economic responsibilities [2]. Secondly, systems that restrict and stimulate the quality of internal audit in universities were not established, which is embodied in the absence of social and industrial supervision systems, thus the audit efficiency and credibility are difficult to be effectively guaranteed. Finally, the independence and authority of the establishment of related institutions are weakened. This leads to that the internal audit staff cannot carry out audit activities objectively or impartially. Although some universities have set up audit offices or offices with auditing functions, the business operational forms are contained by other departments, the functions are confused, and the independence of internal audit is difficult to be practically guaranteed.

\subsection{Analysis from the perspective of internal factors.}

Firstly, the internal audit business procedure in universities lacks normalization, for example, in the initial stage of carrying out the audit activities, relevant personnel did not carry out audit survey, overall analysis of the necessity of audit projects and audit risks was not made, the formulated audit plan had obvious simplicity, the key points were not highlighted, the purposiveness was lacking, in-depth analysis of the feasibility and rationality of the audit planning was not made, and the audit objectives lacked clarity and did not play a leading role on audit activities. Secondly, it comes to the quality of personnel. The overall quality of internal auditing staff in universities is relatively low. At present, as an economic activity with complicated content and form, internal audit needs the involvement of supervision and assessment links, but most of the internal audit staff in universities are not all-side, inter-disciplinary talents, leading to that the quality of the internal audit work cannot be improved for a long time. Finally, relevant systems lack perfection [3]. Most universities only establish corresponding systems when necessary, and the system establishment lacks systematicness, integrality and foreseeability, which is embodied in the detailed rules, regulations and plans for the operation of organization establishment and various internal audit works. If systems related to internal audit have not been established, the efficient operation of audit work is difficult to be effectively guaranteed.

\section{Strategies for establishment of internal audit quality control system in universities}

\subsection{Scientifically setting up internal auditing organizations in universities}

The tenet of the compilation and implementation of this measure is to maintain and strengthen the independence of operation of the internal audit departments. In general, universities should set up auditing department with specific responsibilities, and the principal should be in charge of the department and provide powerful support for operation of the internal audit work [4]. At the same time, the audit strength of government agencies should be actively used, and the supervision and guidance of superior departments in charge should be actively accepted, so as to provide advantageous conditions for smooth operation of the internal audit work. The overall quality of internal audit personnel should be optimized, to be specific, by means of employing inter-disciplinary talents, professional skills and occupation qualities of the auditors should be ensured, thus maintaining the objectivity and impartiality of the operation of internal audit work. In this way, the authenticity and legitimacy of internal audit in universities can be practically safeguarded, the scientificity and completeness of the audit reports can be further improved, and the audit work will inject greater vitality into the realization of sustainable development of education and management in universities. 


\subsection{Establishment and improvement of various rules and regulations of internal audit in universities}

Firstly, the internal audit management regulations for universities should be compiled normatively, internal audit standardized documents should be developed, and the clarity of audit quality standards should be ensured set as the evidence for operation of internal audit. Secondly, the internal audit liability system for universities should be established, so as to ensure the clarity of labor division of internal auditors. For example, ordinary auditors are mainly responsible for investigating the authenticity and integrity of relevant evidence, the audit team leader's responsibility is to evaluate the quality of audit reports, and the audit agency principal needs to manage audit penalties and matters related to the audit office. Third, internal audit review system for universities should be implemented, and auditors should be always set as the principal trial , the audit team leader should timely carry out three-level review on audit working papers. The work objects for audit agency principal are audit reports. The legitimacy of the reports, the rationality of audit disposition, and the operability of audit opinions will be ultimately judged and approved by the principal. Finally, the internal audit quality index system for universities should be established and perfected, and the audit quality can be weighed and assessed by pass rate of the audit working papers and other relevant data. In the face of large internal audit projects, universities should establish the collective discussion system, fully implement the audit recommendations, and globally optimize the efficiency of the operation of internal audit.

\subsection{Strengthening the normalization of internal audit procedures for universities}

Internal audit procedures generally include audit entrustment, audit planning, audit implementation, audit reporting and successive auditing. Strengthening the normalization of internal audit procedures for universities should start from the audit entrustment, and the school management layer should review the authorization, and ensure the work scope and authority limits of internal audit institutions and personnel concerned. At the same time, scientific audit schemes should be actively compiled, the audit risks should be predicted and evaluated on the whole, the audit credentials should be reasonably stored, and the audit work should be practised strictly in accordance with the working procedures, so as to provide convenience for the later audit review work. The effectiveness of information exchanges between the audit department and other relevant departments such as financial department in universities should be strengthened, the most authentic financial reports should be submitted, executable audit opinions should be provided, relevant public disclosure systems of audit information should be established and implemented, critical internal audit information should be publicized through local area network, billboards and other boards, thus giving play to the supervising function of internal audit.

\subsection{Optimizing the internal audit evaluation mechanism of quality in universities}

Optimizing the internal audit evaluation mechanism of quality in universities is one of the effective guarantees for improving the quality of internal audit in universities. Specifically, the internal audit quality assessing index system should be established and implemented, and the qualitative and quantitative assessment indexes should be explicit. To be specific, qualitative indexes include the review of the professional qualification and occupational qualities of auditors as well as the check of their conformance with the operation of internal audit work, the check of the completeness of internal audit agencies in universities, and the check of the timeliness and effectiveness of handling of audit verification issues. Quantitative indexes usually refer to the coverage of university internal audit, the completion rate of audit planning and the repetitive rate of related audit issues of violating laws and rules. Besides, the regular evaluation system of internal audit in universities should be established and improved, and the continuity of audit quality evaluation, the timeliness of audit information disclosure, and the effectiveness of correction of relevant supervision issues should be maintained and enhanced [5]. In addition, relevant reward and punishment mechanisms should be optimized, to be specific, referring to the evaluation results of audit quality, proper spiritual or material rewards should be given to members of the audit project 
team with high-quality operation of internal audit in universities, audit quality assessment should be tactfully associated with the remuneration and post promotion of internal audit staff in universities, and the personnel who made major errors in internal auditing should be appropriately punished and put on records, thus warning against bad examples, continuously strengthening the quality of internal audit staff, and ensuring the audit quality in an constantly improving situation.

\section{Conclusions}

Based on the content of the full paper, a more comprehensive understanding of the significance of the operation of internal audit in universities has been gotten, and several measures to optimize the operation quality of internal audit have been grasped. Relevant personnel should continue to sum up experience and apply new methods in practices, so as to play the functions of the audit department to the utmost extent, ensure the efficiency of the audit work, and make corresponding contributions to the development of universities courses.

\section{References}

[1] Xi Zhihong. Discussion on the Analysis of Factors Affecting the Quality of University Internal Control Audit and the Countermeasures [J]. Economic Research Guide, 2017, (02): 165-166.

[2] Wang Rong. Influencing Factors and Countermeasures of Internal Control Audit Quality in Universities [J]. Journal of Fujian Medical University (Social Science Edition), 2016, 17(03): 21-23.

[3] Guan Xiaoyan. Analysis of the Establishment of University Internal Audit Quality Control System [J], Accounting Learning, 2016, (06): 153-154.

[4] Guo Tiezheng. Problems and Countermeasures of Internal Audit Work in Universities [J]. Journal of Jilin Agriculture Science and Technology College, 2014, 23 (02): 26-28.

[5] Su Liheng, He Guanxing. About the Studies of University Internal Audit Quality Management Measures and Related Assessment and Evaluation Index System [J]. Accountant, 2013, (12): 66-67. 